\title{
The change of health-related quality of life after minimally invasive esophagectomy for esophageal cancer: a meta-analysis
}

\author{
Yong Zhang ${ }^{1 \dagger}$, Xiaomei Yang ${ }^{2 \dagger}$, Donghong Geng ${ }^{3}$, Yingfei Duan ${ }^{4}$ and Junke $\mathrm{Fu}^{1 *}$
}

\begin{abstract}
Background: Short- and long-term health-related quality of life (HRQL) was severely affected after surgery. This study aimed to assess the direction and duration of HRQL from 3- to 24-month follow-ups after minimally invasive esophagectomy (MIE) for esophageal cancer.

Methods: A systematic literature search in MEDLINE, EMBASE, and the Cochrane database was performed for all potentially relevant studies published until February 2017. Studies were included if they addressed the question of HRQL with OERTC-QLQ-C30 and OES18. Primary outcomes were HRQL change at 3-month follow-up. Secondary outcomes were HRQL change from 3-, 6- (short-term) to 12- (mid-term), and/or 24-month (long-term) follow-ups.

Results: Six articles were included to estimate the change in $24 \mathrm{HRQL}$ outcomes after MIE. Most of the patients' HRQL outcomes deteriorated at short-term follow-up and some lasted to mid- or long-term after MIE. Patients' physical function and global QOL deteriorated from short- to long-term follow-ups, and emotional function had no change. The directions of dyspnea, pain, fatigue, insomnia, constipation, diarrhea, cough, and speech problems were increased. The deterioration in global function lasted 6 months, the increase in constipation and speech problems lasted 12 months, and insomnia increased more than 12 months after MIE.
\end{abstract}

Conclusions: The emotional function had no change after MIE. The global QOL become worse during early postoperative period; the symptoms of constipation, speech problems, and insomnia increased for a long time after MIE.

Keywords: Esophageal cancer, Health-related quality of life (HRQL), Minimally invasive esophagectomy (MIE), Meta-analysis

\section{Background}

Esophageal cancer is one of the most common malignant tumors of the digestive system with a poor prognosis with overall 5 -year survival rates only $15-50 \%$, and the incidence of esophageal cancer has risen steadily during recent decades [1-3]. Esophagectomy with lymphadenectomy is regarded as the only curative option for patients with resectable esophageal cancer [4-6].

The traditional open esophagectomy (OE) is a relatively high invasive surgery, which may lead to several morbidities or prominent mortality [7]. Minimally invasive surgery is assumed to reduce surgical injury and improve patients'

\footnotetext{
* Correspondence: fujunk-6612@126.com

†Yong Zhang and Xiaomei Yang contributed equally to this work. 'Department of Thoracic Surgery, the First Affiliated Hospital of Xi'an Jiaotong University, No. 277 West Yanta Road, Xi'an 710061, China Full list of author information is available at the end of the article
}

prognosis. With the developing skills and increasing experiences in laparoscopy and thoracoscopy in thoracic and stomach surgery, minimally invasive esophagectomy (MIE) has become the recommended approach, popularized in centers with experienced surgeons [8].

A lot of longitudinal and meta-analysis studies have been performed to compare the outcomes of OE with MIE, which conclude that MIE is a safe alternation or better choice for esophageal cancer to OE because patients undergoing MIE may benefit from shorter hospital stay, lower complications, less morbidity, and overall survival [9-12]. Studies that investigate health-related quality of life (HRQL) after surgery for esophageal cancer show that patients will experience an impaired quality of life post operation, and MIE had an overall benefit on quality of life (QOL) for the patients compared with open surgery [13-20]. However, 
few studies focus on assessing the impact of MIE for esophageal cancer on HRQL and the change of HRQL after surgery $[13,18]$. On this basis, the aim of this meta-analysis is to analyze the change of short- to long-term QOL after MIE for esophageal cancer.

\section{Methods}

\section{Search strategies}

A MEDLINE, EMBASE, and Cochrane database search was performed by two authors on all relevant clinical studies published until February 2017, analyzing quality of life after minimally invasive esophagectomy for esophageal cancer. The following keywords and medical subject headings were used: esophageal neoplasms, esophageal cancer, esophagus cancer, esophagus carcinoma, oesophageal cancer, esophageal carcinoma, oesophageal carcinoma, cancer of esophagus, carcinoma of esophagus, esophagectomy, resection of esophagus, minimally invasive surgical procedures, minimally invasive surgery, video-assisted thoracic surgery, thoracoscopic, thoracoscopy, laparoscopic, laparoscopy, quality of life, life quality, living quality, and quality of lives. Only studies on humans and written in English were considered for inclusion. The related-articles function was used to expand the search from each identified relevant study. A manual cross-reference search from articles was also performed. All citations and abstracts identified were thoroughly reviewed. The latest date for this search was 20 February 2017. Data quoted as unpublished or data from abstracts were not used. Any disagreements regarding which studies should be included that existed in two researchers were resolved through discussion.

\section{Inclusion and exclusion criteria}

Studies were selected if they reported on a series of patients who underwent minimally invasive esophagectomy because of esophageal cancer. Procedures of minimally invasive esophagectomy included thoracoscopy combined with laparotomy or laparoscopy.

All studies included in this meta-analysis also required to present detailed information used to assess quality of life and on when the questionnaire was administered. Only those were selected when all patients filled out the questionnaires before operation and at the follow-up $(3,6,12$, and/ or 24 months after operation) by letter visit or out-patient consultant. Questionnaires that were used to analyze HRQL included, but not limited to, European Organization for Research and Treatment of Cancer (EORTC) QLQ C30 and OES18. Those that only presented their results graphically were excluded. When studies were discovered to report (partially) similar patient data, only the most recent and complete data sets were included.

\section{Data extraction}

Data was extracted independently by two reviewers (XM Yang and YF Duan) from each study: study characteristics (first author, year of publication, study design, study aim, timing of follow-up and HRQL data gathering, and type of questionnaire used), population characteristics (number of patients included, demographics, cancer histologic type, cancer stage, cancer site, and neoadjuvant therapy), item, and total results.

We contacted the first or corresponding author of each article by e-mail if not all descriptive outcome data was reported. If necessary, we used reported $95 \%$ confidence intervals (95\% CIs), standard errors, to transform missing SD data [21].

\section{Interested outcomes}

The primary outcome of this study was HRQL change at 3-month follow-up. The second outcome was HRQL change from 3-, 6- (short-term) to 12- (mid-term), and/ or 24-month (long-term) follow-ups.

The studies were included when both the following validated quality of life instruments were used: the EORTCQLQ-C30 and the EORTC-QLQ-OES18. The QLQ-C30 questionnaire was developed by the Quality of Life Division of EORTC. It explored the generic quality of life of patients affected by oncologic diseases and includes a global health status scale, five functional scales (physical, role, emotional, cognitive, and social), three symptom scales (fatigue, nausea and vomiting, and pain), and six single items (dyspnea, insomnia, anorexia, constipation, diarrhea, and financial difficulties) [13]. The QLQ OES-18 assessed symptoms specific to esophageal cancer and was composed of four symptom scales (dysphagia, eating, reflux, and esophageal pain) and six single items (swallowing saliva, choking when swallowing, dry mouth, taste problem, coughing, and speech problem) [14]. Each item had four response alternatives: "not at all" (scored as 1), "a little" (scored as 2), "quite a bit" (scored as 3), and "very much" (scored as 4), except for the global QOL scale which ranges from "very poor" (scored as 1) to "excellent" (scored as 7). All QLQ-C30 and QLQOES18 responses were transformed linearly to scores ranging from 0 to 100.

\section{Statistical analysis}

Review Manager Version 5.3 (Copenhagen: the Nordic Cochrane Centre, The Cochrane Collaboration, 2014) was used to perform meta-analysis. The data can be synthesized only when the number of studies exceeds two. Measurement data reported as mean $\mathrm{SD} / \mathrm{SE}$ were adopted. The results were presented as weighted mean differences [95\% confidence interval (CI)]. Heterogeneity was assessed by $\chi^{2}$ and $I^{2}$. An $I^{2}<30 \%$ represented low heterogeneity, 30-50\% moderate, $50-75 \%$ substantial, and $75-100 \%$ considerable heterogeneity $[7,22]$. The statistical results used fixed-effect models for low 
and moderate heterogeneity, random-effect models for substantial and considerable heterogeneity. The study design and risk of bias are shown in Table 1. The definitions of direction, clinical relevance, and duration of HRQL change were same as those described by Jacobs et al. [13].

\section{Results}

\section{Selected studies}

A flowchart of the literature screening process is shown in Fig. 1. The initial search yielded 1337 articles, of which 1306 were excluded based on their titles. Fifteen duplicated articles were then manually excluded on the basis of their titles. Three articles were excluded because of not being written in English. Eight articles were further excluded on the basis of their abstracts or full texts, of which two were conference abstracts [23, 24]; one was comment [25], one was systematic review [14], two presented their results only in graphical formats [26, 27], one presented their results only in percent of patients [28], one was related to the reliability and validity of the questionnaire [22], and one article was included based on the cross-reference search [17]. Six articles finally met the criteria of inclusion [15-20], and two reported data form the same hospital by the same first author $[15,19]$. Although they reported the same dataset, two studies from Zhongshan Hospital were included in the analysis because one analyzed more aspects of HRQL $[15,19]$. However, all the patients included in these studies were counted only once, and only the most recent and complete data sets were selected.

\section{Characteristics of studies and patients}

The selected trials included a total of six studies that were published between 2010 and 2016 (Table 2), of which two were retrospective studies $[15,19]$, three were prospective ones [16-18], and only one was a randomized controlled trial (RCT) [20]. One study was done in Australia [17], one in Belgium [18], two in China [15, 19], one in the UK [16], and the last one in the Netherlands [20]. Five studies used both EORTC QLQ C30 and the disease-specific OES18 questionnaires. One study was performed not only using EORTC QLQ C30 and the disease-specific OES18, but also SF36. The HRQL was the primary outcome for all studies. Patients were all enrolled consecutively. The measure times of HRQL were preoperation (baseline), 3-, 6-, 12-, and/or 24-month postoperation. One study aimed to assess HRQL after MIE [16], and five studies aimed to compare HRQL in patients after MIE and open esophagectomy [15, 17-20].

The number of patients included in the selected trials was 1034, of which 848 were males. The range of mean ages reported by different papers was 56 to 67 years. The indication for surgery was esophageal adenocarcinoma in 442 patients, squamous cell carcinoma in 576 patients, and others in 16 patients. The pathological TNM stages were stage 0 and stage I in 279 cases, stage II in 444 cases, stage III in 262 cases, and stage IV in 36 cases. All patients received neoadjuvant chemo- or chemoradiotherapy in one study [20]; no patients received in two studies [15, $18]$; and partial patients received in three studies $[16,17$, 19]. All patients received a combination of general and epidural anesthesia during the operation. In the first 3-5 days after surgery, patients received epidural or intravenous analgesia. The follow-up duration after esophagectomy, as reported in the articles, was between 6 and 72 months. The characteristics of the patients included in each study are described in Table 3.

\section{HRQL change}

Twenty-four HRQL outcomes were included in our meta-analysis. Mean difference with 95\% confidence intervals are reported in Table 4, which also reflects the average HRQL change.

\section{Primary outcomes}

The direction and clinical relevance of HRQL change at 3-month follow-up are shown in Table 5. Patients' physical function, role function, and global QOL deteriorated. All symptoms in QLQ-C30 and dry mouth, cough problem, and speech problem in QLQ-OES18 increased. However, the direction for other outcomes (three functional scales in QLQ-C30, four symptom scales, and two single items in QLQ-OES18) at 3-month follow-up were too heterogeneous to interpret.

Table 1 The study design and risk of bias of studies included in the meta-analysis

\begin{tabular}{|c|c|c|c|c|c|c|c|c|}
\hline \multirow[t]{2}{*}{ The first author } & \multirow{2}{*}{$\begin{array}{l}\text { Study } \\
\text { design }\end{array}$} & \multicolumn{7}{|l|}{ Risk of bias } \\
\hline & & $\begin{array}{l}\text { Sequence } \\
\text { generation }\end{array}$ & $\begin{array}{l}\text { Allocation } \\
\text { concealment }\end{array}$ & $\begin{array}{l}\text { Blinding patient } \\
\text { /personnel }\end{array}$ & $\begin{array}{l}\text { Incomplete } \\
\text { outcome data }\end{array}$ & $\begin{array}{l}\text { Blinding } \\
\text { outcome }\end{array}$ & $\begin{array}{l}\text { Selective outcome } \\
\text { reporting }\end{array}$ & $\begin{array}{l}\text { Other source } \\
\text { of bias }\end{array}$ \\
\hline Barbour et al. [17] & Cohort & High & High & High & Unclear & High & Low & Low \\
\hline Wang et al. [19] & Cohort & High & High & High & Unclear & High & Low & Low \\
\hline Maas et al. [20] & $\mathrm{RCT}$ & Low & High & High & Low & High & Low & Low \\
\hline Wang et al. [15] & Cohort & High & High & High & Unclear & High & Low & Low \\
\hline $\begin{array}{l}\text { Parameswaran et } \\
\text { al. [16] }\end{array}$ & $\begin{array}{l}\text { Case } \\
\text { series }\end{array}$ & N/A & N/A & N/A & N/A & High & Low & Low \\
\hline Nafteux et al. [18] & Cohort & High & High & High & Unclear & High & Low & High \\
\hline
\end{tabular}




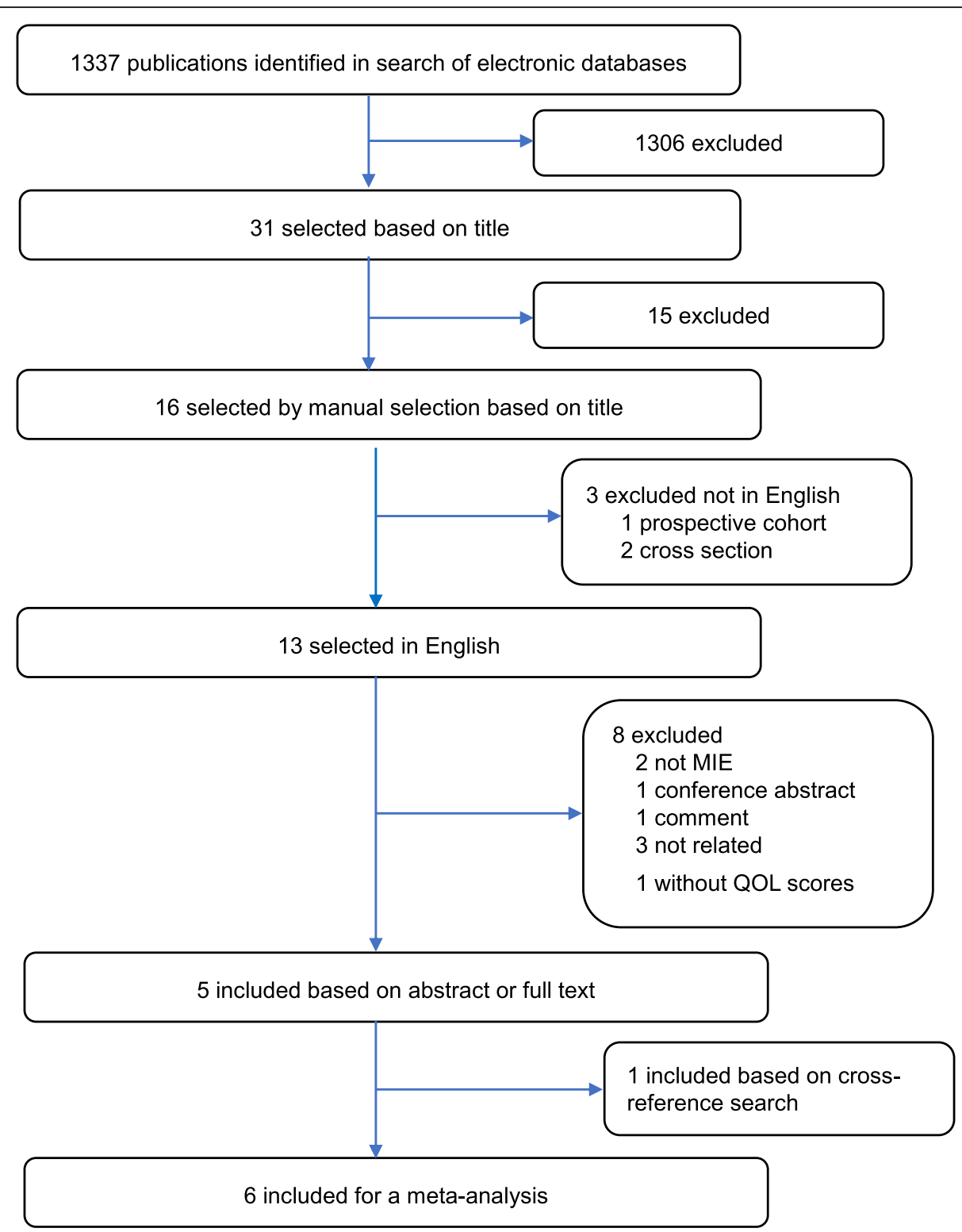

Fig. 1 Flowchart of literature identification and screening process

The global QOL, insomnia, financial problem, and speech problem changes were small, which showed clinical relevance at 3-month follow-up. However, other HRQL outcomes (five functional scales, three general symptom scales and four single items in QLQ-C30, and four symptom scales and four single items in QLQ-OES 18) did not show clinical relevance.

\section{Secondary outcomes}

The direction and duration of HRQL change at 3-, 6-, 12-, and/or 24-month follow-ups are reported in Table 5. The directions of patients' physical function and global QOL deteriorated, and emotional function had no change. The directions of dyspnea, pain, fatigue, insomnia, constipation, diarrhea, cough problem, and speech problem were increased. However, the direction for other outcomes (three functional scales and two single items in QLQ-C30 and four symptom scales and three single items in QLQ-OES 18) at 3-, 6-, 12-, and/or 24-month follow-ups were too heterogeneous to interpret.

The deterioration in global function lasted 6 months after surgery. The increase in constipation and speech problem lasted 12 months after surgery. And, symptoms of insomnia increased more than 12 months after surgery. However, the duration for other outcomes (four functional scales, three general symptom scales and three single items in QLQ-C30, and four symptom scales and four single items in QLQ-OES 18) were too heterogeneous to interpret. 


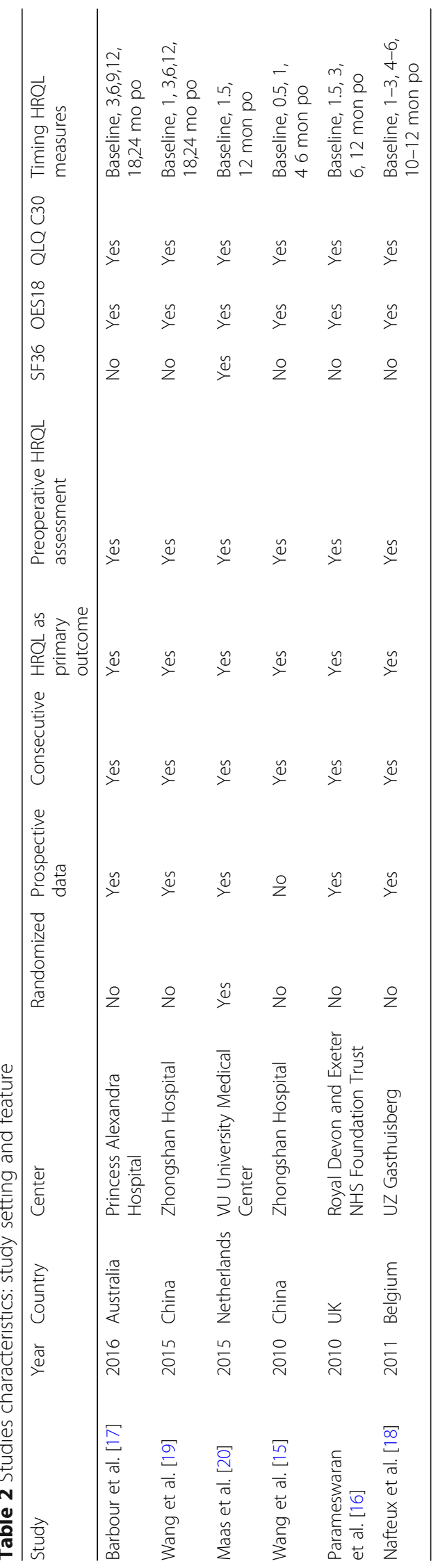




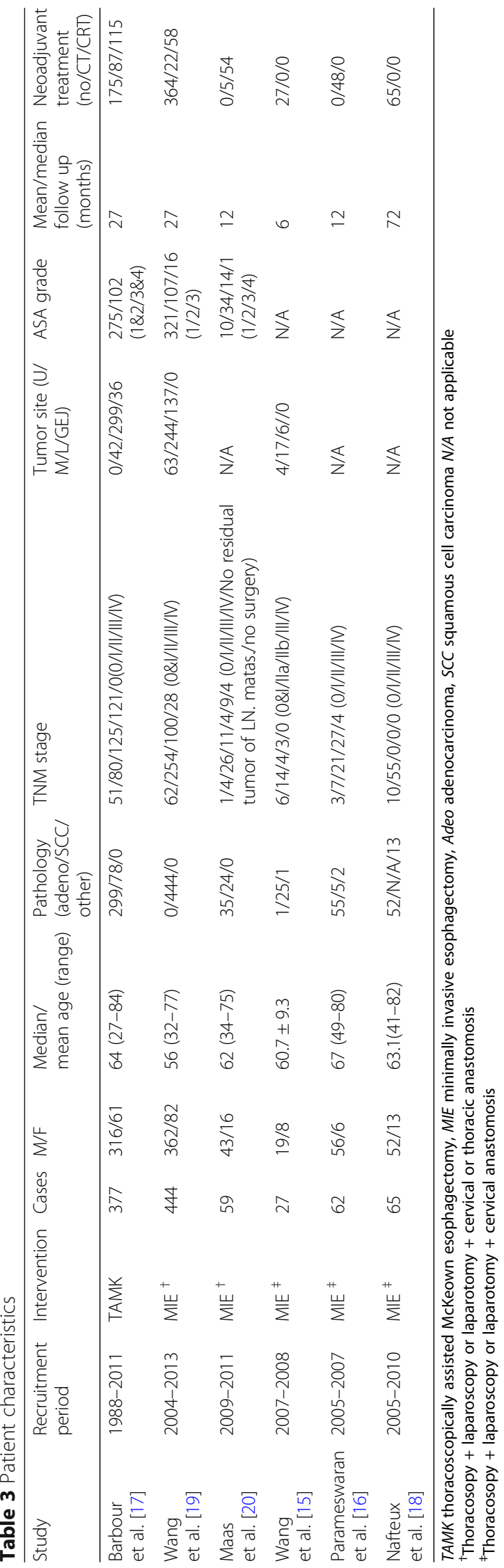




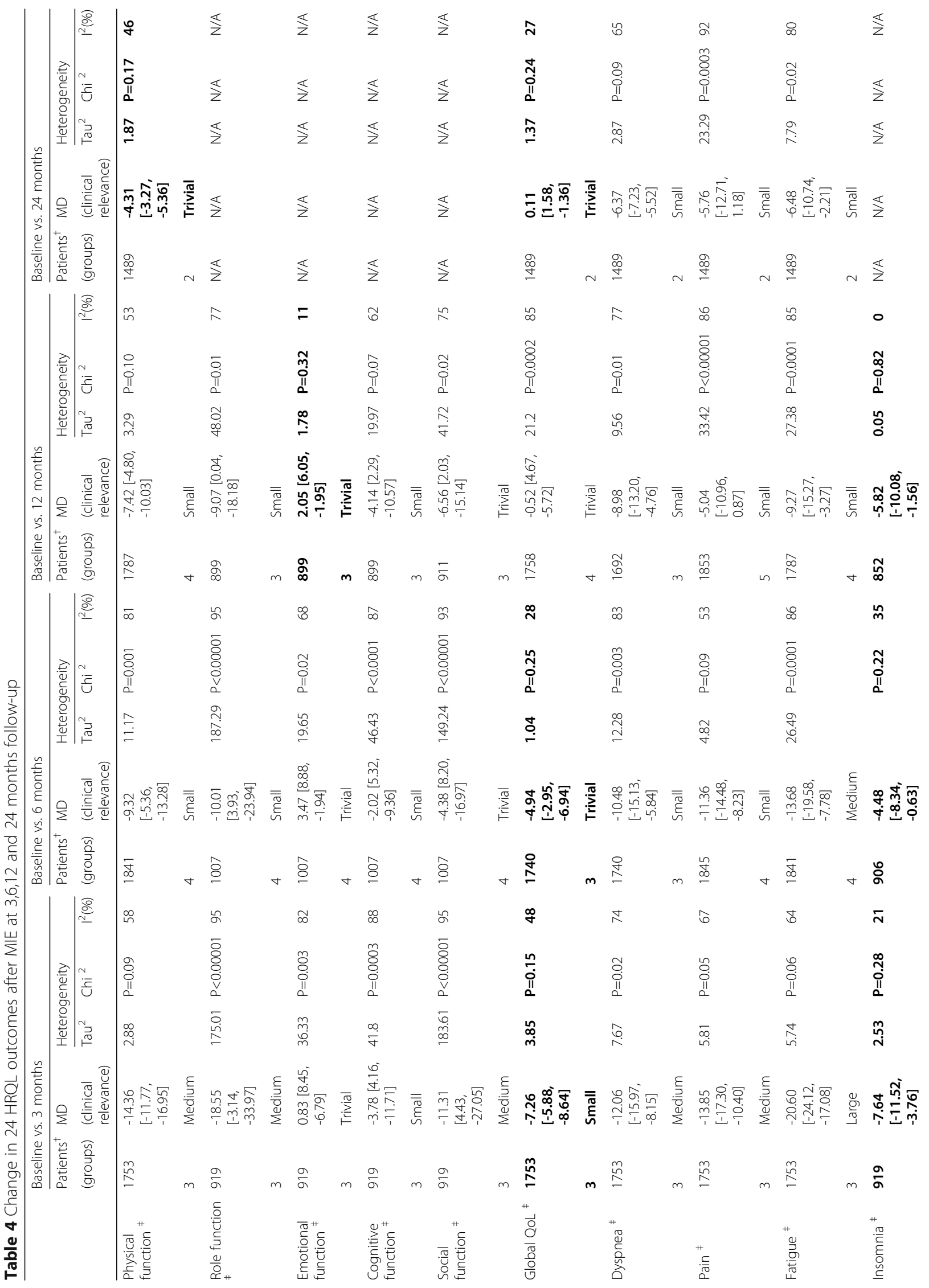




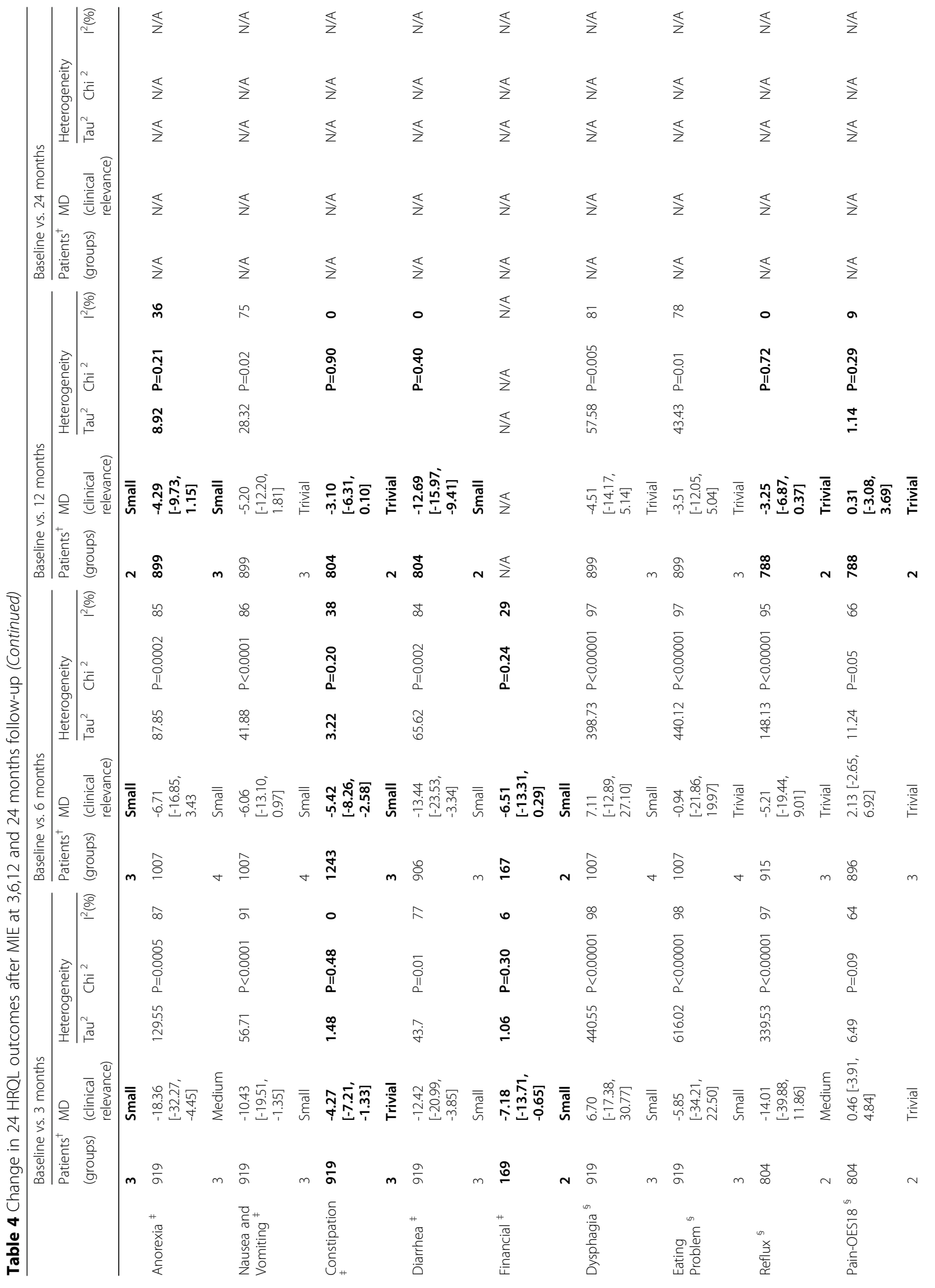




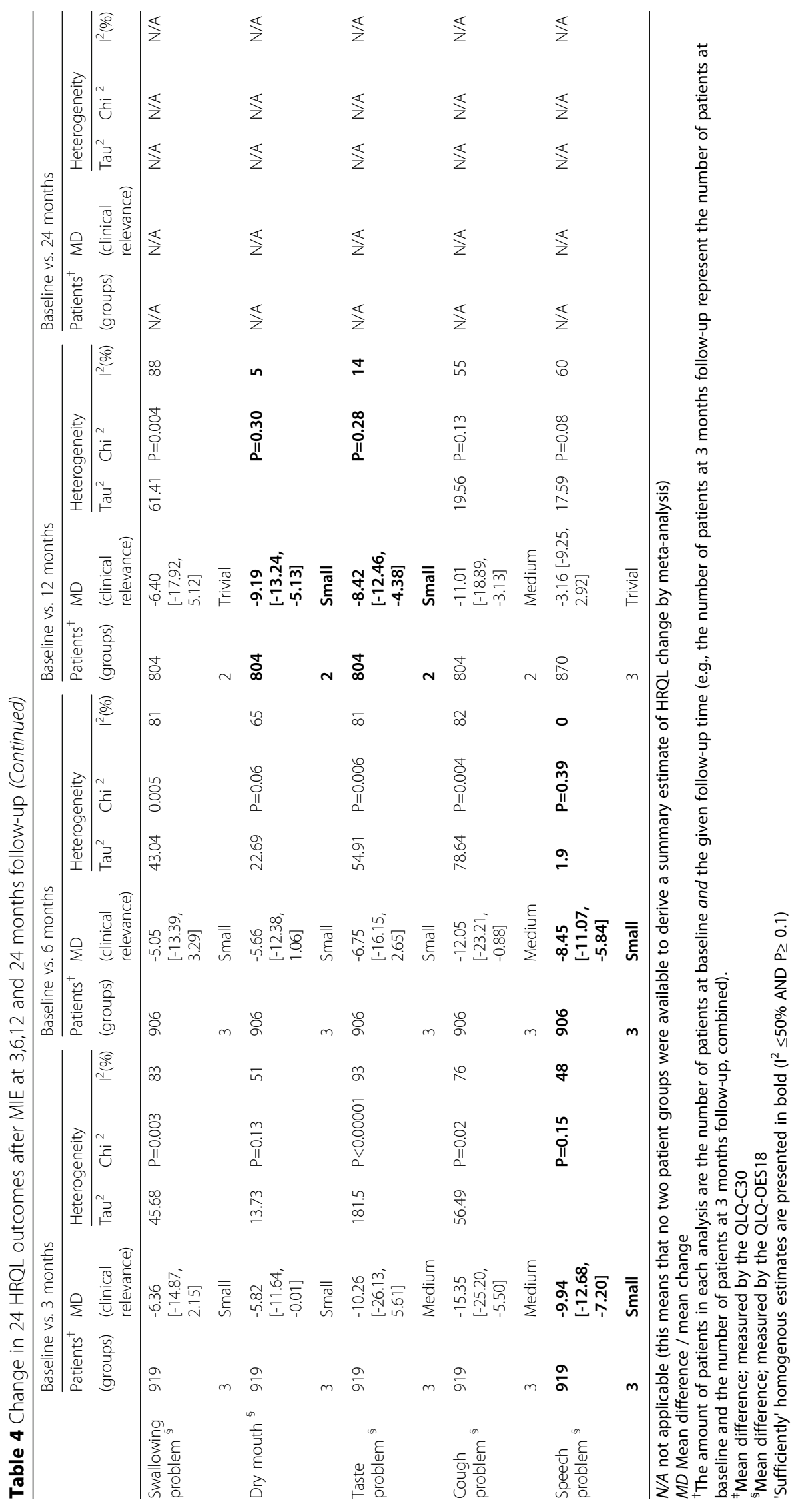


Table 5 Main analysis for the direction, clinical relevance, and duration of change in 24 HRQL outcomes after MIE

\begin{tabular}{|c|c|c|c|c|c|c|}
\hline \multirow[t]{2}{*}{$\begin{array}{l}\text { HRQL } \\
\text { outcome }\end{array}$} & \multicolumn{4}{|c|}{ HRQL change at 3-month follow-up } & \multicolumn{2}{|c|}{$\begin{array}{l}\text { HRQL change at 3-, 6-12-,and } \\
\text { /or } 24 \text { month follow-ups }\end{array}$} \\
\hline & $\begin{array}{l}\text { Number of } \\
\text { patients }^{\dagger} \\
\text { (Groups) }\end{array}$ & $\begin{array}{l}\text { Amount of } \\
\text { heterogeneity }^{\ddagger}\end{array}$ & $\begin{array}{l}\text { Direction of HRQL } \\
\text { change }^{\text {s,a }}\end{array}$ & $\begin{array}{l}\text { Clinical relevance } \\
\text { of HRQL change }\end{array}$ & $\begin{array}{l}\text { Direction of HRQL } \\
\text { change }^{\S, \mathbb{q}, \neq \neq}\end{array}$ & $\begin{array}{l}\text { Duration of } \\
\text { HRQL } \\
\text { change }^{\S \S}\end{array}$ \\
\hline $\begin{array}{l}\text { Physical } \\
\text { function }\end{array}$ & $1753(3)$ & Substantial & Deterioration & Unclear & Deterioration & Unclear \\
\hline Role function & 919 (3) & Considerable & Deterioration & Unclear & Unclear & Unclear \\
\hline $\begin{array}{l}\text { Emotional } \\
\text { function }\end{array}$ & $919(3)$ & Considerable & Unclear & Unclear & No change & No change \\
\hline $\begin{array}{l}\text { Cognitive } \\
\text { function }\end{array}$ & 919 (3) & Considerable & Unclear & Unclear & Unclear & Unclear \\
\hline Social function & 919 (3) & Considerable & Unclear & Unclear & Unclear & Unclear \\
\hline Global QoL & $1753(3)$ & Moderate & Deterioration & Small & Deterioration & 6 months \\
\hline Dyspnea & $1753(3)$ & Substantial & Increase & Unclear & Increase & Unclear \\
\hline Pain & $1753(3)$ & Substantial & Increase & Unclear & Increase & Unclear \\
\hline Fatigue & $1753(3)$ & Substantial & Increase & Unclear & Increase & Unclear \\
\hline Insomnia & 919 (3) & Low & Increase & Small & Increase & $>12$ months 9 \\
\hline Anorexia & 919 (3) & Considerable & Increase & Unclear & Unclear & Unclear \\
\hline Nausea and Vomiting & 919 (3) & Considerable & Increase & Unclear & Unclear & Unclear \\
\hline Constipation & 919 (3) & Low & Increase & Trivial & Increase & 12 months \\
\hline Diarrhea & 919 (3) & Considerable & Increase & Unclear & Increase & Unclear \\
\hline Financial & $169(2)$ & Low & Increase & Small & N/A & N/A \\
\hline Dysphagia & 919 (3) & Considerable & Unclear & Unclear & Unclear & Unclear \\
\hline $\begin{array}{l}\text { Eating } \\
\text { Problem }\end{array}$ & 919 (3) & Considerable & Unclear & Unclear & Unclear & Unclear \\
\hline Reflux & $804(2)$ & Considerable & Unclear & Unclear & Unclear & Unclear \\
\hline Pain-OES18 & $804(2)$ & Substantial & Unclear & Unclear & Unclear & Unclear \\
\hline $\begin{array}{l}\text { Swallowing } \\
\text { problem }\end{array}$ & 919 (3) & Considerable & Unclear & Unclear & Unclear & Unclear \\
\hline Dry mouth & 919 (3) & Substantial & Increase & Unclear & Unclear & Unclear \\
\hline Taste problem & 919 (3) & Considerable & Unclear & Unclear & Unclear & Unclear \\
\hline $\begin{array}{l}\text { Cough } \\
\text { problem }\end{array}$ & 919 (3) & Considerable & Increase & Unclear & Increase & Unclear \\
\hline $\begin{array}{l}\text { Speech } \\
\text { problem }\end{array}$ & 919 (3) & Moderate & Increase & Small & Increase & 12 months \\
\hline
\end{tabular}

${ }^{\dagger}$ The number of patients included at baseline and the number of patients included at 3-month follow-up, combined

${ }^{\ddagger}$ We used the $I^{2}$ statistic to describe the percentage of inconsistency attributable to heterogeneity and not chance. An $I^{2}$ of $<30 \%$ represents low heterogeneity, 30-50\% moderate, 50-75\% substantial, and $75-100 \%$ considerable heterogeneity

${ }^{\S}$ The direction of HRQL change was clear if the estimate was "sufficiently" homogenous (i.e., $X^{2} P \geq 0.1$ and $l^{2}$ low or moderate) or, when the estimate was not "sufficiently" homogenous, if both the summary estimate and confidence intervals reported the same direction [e.g., $-5,00(-10,00 ;-2,00)]$

For functioning scores, "deterioration" indicates that the follow-up scores were lower than baseline scores. For symptom scales, "increase" indicates that the follow-up scores were higher than baseline scores

"The clinical relevance of HRQL change was clear if the estimate was "sufficiently" homogenous (i.e., $X^{2} P \geq 0.1$ and $l^{2}$ low or moderate)

${ }^{+\dagger} \mathrm{A}$ large change indicates a clear clinical relevance. A medium change indicates a clinical relevance, but to a lesser extent. A small change indicates a subtle but nevertheless clinically relevant effect. A trivial change indicates either a change of unlikely clinical relevance, or no change

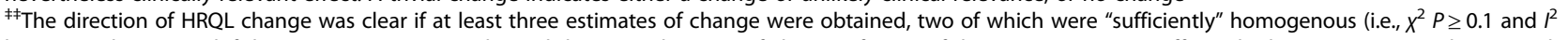
low or moderate), and if the summary estimates showed the same direction of change. If none of the estimates were "sufficiently" homogenous, we determined that the direction of HRQL change was clear if the summary estimates and confidence intervals at 3-, 6-, 9-, and 12-month follow-ups showed the same direction of change [e.g., $-5,00(-10,00 ;-2,00)]$

${ }^{\S 5}$ The duration of HRQL change was clear if at least three estimates of HRQL change were obtained (e.g., at 3-, 9-, and 12-month follow-ups). Two of these estimates had to be "sufficiently" homogenous (i.e., $X^{2} P \geq 0.1$ and $l^{2}$ low or moderate)

The duration of HRQL change lasted longer if the clinical relevance of the last sufficiently homogenous estimate was not trivial or if subsequent estimates were not "sufficiently homogenous" 


\section{Discussion}

Several studies had shown that open esophagectomy has a negative impact on almost all aspects of HRQL, and it would take 9-12 months to return to levels before operation [29-31]. Others reported that HRQL recovered more quickly after MIE than OE [15, 17-20].

This is the first meta-analysis to estimate the clinical relevance and duration of change for 24 HRQL outcomes from short- to long-term after MIE. After MIE, patients' emotional function has no change from short- to mid-term follow-up; global QOL deteriorated only at short-term follow-up. Symptoms of constipation and speech problem increased from short- to mid-term follow-up, and insomnia increased up to long-term follow-up. In addition, global QOL, most functional scales, and most symptoms have negative change at short-term follow-up and keep the trend to mid- and/or long-term follow-up. However, the clinical relevance and the duration of most change cannot be interpreted because of huge heterogeneity.

The clinical heterogeneity of the studies focusing on HRQL after esophagectomy has been presented in many studies. Levenstein et al. [32] assessed HRQL by an international comparison. The study showed that HRQL varied from one country to another because of differences in social, cultural, medical systems, race, family structure, and/or economic determinants with relevance to the patient-physician relationship, patient education, and therapeutic decision making, and other factors. Comorbidity, tumors located in the middle or upper esophagus, SCC histology, tumors in stages III and IV have been reported to be associated with worse HRQL. And, patients with early disease stages had better HRQL than those with more locally advanced disease [33, 34].

It is still controversial whether patients receiving neoadjuvant chemotherapy or chemoradiotherapy had worse HRQL than those who underwent esophagectomy alone. Blazeby et al. [35] reported that patients who received palliative treatment had significantly worse pain, fatigue, appetite loss, constipation, and dysphagia. Other studies had shown that preoperative chemotherapy or chemoradiotherapy had a temporarily negative impact on HRQL, which returned to baseline levels before surgery, and recovery of HRQL after esophagectomy was not impaired by neoadjuvant treatment [29, 36]. In contrast, Ariga et al. [37] observed that patients with squamous cell carcinoma who underwent definitive chemoradiation had similar general HRQL scores and lower diarrhea, appetite loss, and eating problem scores than those who had undergone surgery alone.

The surgical approach (MIE vs. OE) and the length of the postoperative time period have been presented that had a positive impact on patients' postoperative QOL (global QOL, physical function, fatigue symptoms, pain symptoms, and dyspnea symptoms) [19]. And conservative, non-definitive treatments such as endoscopic treatment may cause more fear of recurrence than esophagectomy, which may have negative effect on HRQL [38].

It is impossible, up to now, to get enough homogeneous studies to analyze HRQL after MIE [13, 14]. In other words, the heterogeneities of studies included in our meta-analysis were unavoidable. Studies from five different countries were included. The tumor histology and tumor stage were different from one study to another. Whether neoadjuvant treatments were performed varied among the included studies.

Our study has some limitations. First, we selected more retrospective studies, and only one randomized controlled trial. Only one study aimed to assess the impact of MIE on HRQL, others aimed to compare HRQL between MIE an OE. Second, there were not enough studies available to investigate the influence of MIE on HRQL [39]. Third, we chose studies reported in English, but omitted non-English studies [40]. All these might lead to bias. Therefore, more randomized controlled trials are needed to validate HRQL after MIE.

\section{Conclusions}

This meta-analysis shows that the emotional function had no change after operation. The global function became worse during the early postoperative period; the symptoms of constipation, speech problem, and insomnia increased for a long time after operation.

\section{Abbreviations}

EORTC: European Organization for Research and Treatment of Cancer; HRQOL: Health-related quality of life; MIE: Minimally invasive esophagectomy; OE : Open esophagectomy; QLQ: Quality of life questionnaire

\section{Acknowledgements}

We thank Hai-rong He for her help on the study design and data analysis. We also thank Zhengwang Wu (Department of Radiology, University of North Carolina), Shaoyi Du, Yiting Xu, Wenting Cui, and Teng Wan (Institute of Artificial Intelligence and Robotics, Xi'an Jiaotong University) for their language edit.

\section{Funding}

This work was supported by the Fundamental Research Funds for the Central University of China [No.08143004] in the design of the study and collection, analysis, and interpretation of data, by the Funds for Science and Technology Project of Shaanxi Province of China [No. 2014 K11-02-03-07] in writing the manuscript.

\section{Availability of data and materials}

The datasets generated during and/or analyzed during the current study are available in the MEDLINE, EMBASE, and Cochrane databases.

\section{Authors' contributions}

YZ and JKF designed and wrote the manuscript. XMY and YFD extracted the data from each study and analyzed the data. DHG and XMY were major contributors in writing the manuscript. All authors read and approved the final manuscript.

Ethics approval and consent to participate Not applicable

Consent for publication Not applicable 


\section{Competing interests}

The authors declare that they have no competing interests.

\section{Publisher's Note}

Springer Nature remains neutral with regard to jurisdictional claims in published maps and institutional affiliations.

\section{Author details}

'Department of Thoracic Surgery, the First Affiliated Hospital of Xi'an Jiaotong University, No. 277 West Yanta Road, Xi'an 710061, China. ${ }^{2}$ Hospital 521 of China's Ordnance Industry Group, Xi'an 710065, China. ${ }^{3}$ School of Continuing Education of Xi'an Jiaotong University, Xi'an 710061, China. ${ }^{4}$ Department of Pathology, the First Affiliated Hospital of Xi'an Jiaotong University, Xi'an 710061, China.

Received: 5 November 2017 Accepted: 4 February 2018

Published online: 24 May 2018

\section{References}

1. Rutegard M, Charonis K, Lu Y, Lagergren P, Lagergren J, Rouvelas I. Population-based esophageal cancer survival after resection without neoadjuvant therapy: an update. Surgery. 2012;152:903-10.

2. van Hagen P, Hulshof MC, van Lanschot JJ, Steyerberg EW, van Berge Henegouwen MI, Wijnhoven BP, Richel DJ, Nieuwenhuijzen GA, Hospers GA, Bonenkamp JJ, et al. Preoperative chemoradiotherapy for esophageal or junctional cancer. N Engl J Med. 2012;366:2074-84

3. Miller KD, Siegel RL, Lin CC, Mariotto AB, Kramer JL, Rowland JH, Stein KD, Alteri $\mathrm{R}$, Jemal A. Cancer treatment and survivorship statistics, 2016. CA Cancer J Clin. 2016:66:271-89.

4. Enzinger PC, Mayer RJ. Esophageal cancer. N Engl J Med. 2003;349:2241-52.

5. Wu PC, Posner MC. The role of surgery in the management of oesophageal cancer. Lancet Oncol. 2003:4:481-8.

6. Sjoquist KM, Burmeister BH, Smithers BM, Zalcberg JR, Simes RJ, Barbour A Gebski V, Australasian Gastro-Intestinal Trials G. Survival after neoadjuvant chemotherapy or chemoradiotherapy for resectable oesophageal carcinoma: an updated meta-analysis. Lancet Oncol. 2011;12:681-92.

7. Jamieson GG, Mathew G, Ludemann R, Wayman J, Myers JC, Devitt PG. Postoperative mortality following oesophagectomy and problems in reporting its rate. Br J Surg. 2004;91:943-7.

8. Luketich JD, Pennathur A, Awais O, Levy RM, Keeley S, Shende M, Christie NA Weksler B, Landreneau RJ, Abbas G, et al. Outcomes after minimally invasive esophagectomy: review of over 1000 patients. Ann Surg. 2012;256:95-103.

9. Yerokun BA, Sun Z, Jeffrey Yang CF, Gulack BC, Speicher PJ, Adam MA, D'Amico TA, Onaitis MW, Harpole DH, Berry MF, Hartwig MG. Minimally Invasive Versus Open Esophagectomy for Esophageal Cancer: A PopulationBased Analysis. Ann Thorac Surg. 2016;102:416-23.

10. Sihag S, Kosinski AS, Gaissert HA, Wright CD, Schipper PH. Minimally Invasive Versus Open Esophagectomy for Esophageal Cancer: A Comparison of Early Surgical Outcomes From The Society of Thoracic Surgeons National Database. Ann Thorac Surg. 2016;101:1281-8. discussion 1288-1289

11. Yibulayin W, Abulizi S, Lv H, Sun W. Minimally invasive oesophagectomy versus open esophagectomy for resectable esophageal cancer: a metaanalysis. World J Surg Oncol. 2016;14:304.

12. Zhou C, Zhang L, Wang H, Ma XX, Shi BH, Chen WK, He JJ, Wang K, Liu PJ, Ren Y. Superiority of Minimally Invasive Oesophagectomy in Reducing InHospital Mortality of Patients with Resectable Oesophageal Cancer: A MetaAnalysis. PLoS One. 2015:10

13. Jacobs M, Macefield RC, Elbers RG, Sitnikova K, Korfage IJ, Smets EM, Henselmans I, van Berge Henegouwen MI, de Haes JC, Blazeby JM, Sprangers MA. Meta-analysis shows clinically relevant and long-lasting deterioration in health-related quality of life after esophageal cancer surgery. Qual Life Res. 2014;23:1097-115.

14. Scarpa M, Valente S, Alfieri R, Cagol M, Diamantis G, Ancona E, Castoro C. Systematic review of health-related quality of life after esophagectomy for esophageal cancer. World J Gastroenterol. 2011;17:4660-74

15. Wang H, Feng M, Tan L, Wang Q. Comparison of the short-term quality of life in patients with esophageal cancer after subtotal esophagectomy via videoassisted thoracoscopic or open surgery. Dis Esophagus. 2010;23:408-14.

16. Parameswaran R, Blazeby JM, Hughes R, Mitchell K, Berrisford RG, Wajed SA. Health-related quality of life after minimally invasive oesophagectomy. $\mathrm{Br}$ J Surg. 2010;97:525-31.
17. Barbour AP, Mc Cormack OM, Baker PJ, Hirst J, Krause L, Brosda S, Thomas JM Blazeby JM, Thomson IG, Gotley DC, Smithers BM. Long-Term Health-related Quality of Life Following Esophagectomy: A Nonrandomized Comparison of Thoracoscopically Assisted and Open Surgery. Ann Surg. 2016;

18. Nafteux P, Moons J, Coosemans W, Decaluwe H, Decker G, De Leyn P, Van Raemdonck D, Lerut T. Minimally invasive oesophagectomy: a valuable alternative to open oesophagectomy for the treatment of early oesophageal and gastro-oesophageal junction carcinoma. Eur J Cardiothorac Surg. 2011:40:1455-63. discussion 1463-1454

19. Wang $H$, Shen $Y$, Feng $M$, Zhang $Y$, Jiang $W$, Xu S, Tan L, Wang Q. Outcomes, quality of life, and survival after esophagectomy for squamous cell carcinoma: A propensity score-matched comparison of operative approaches. J Thorac Cardiovasc Surg. 2015;149:1006-14. discussion 10141005.e1004

20. Maas KW, Cuesta MA, van Berge Henegouwen MI, Roig J, Bonavina L, Rosman C, Gisbertz SS, Biere SS, van der Peet DL, Klinkenbijl JH, et al. Quality of Life and Late Complications After Minimally Invasive Compared to Open Esophagectomy: Results of a Randomized Trial. World J Surg. 2015; 39:1986-93.

21. Higgins JP, Green S. Cochrane Handbook for Sys-tematic Reviews of Interventions Version 5.1.0 [updated March 2011]. The Cochrane Collaboration, 2011. Available from www.cochrane-handbook.org. Accessed 27 Aug 2012

22. Castoro C, Scarpa M, Cavallin F, Saadeh L, Pinto E, Alfieri R, Cagol M, Da Roit A, Pizzolato E, Noaro G, Pozza G. Impact of hybrid minimally invasive esophagectomy for cancer on quality of life. Surg Endosc Other Interv Tech. 2016;30:S133.

23. Cormack OM, Barbour A, Baker P, Hirst J, Thomas J, Blazeby J, Thomson I, Gotley D, Smithers B. Long-term health related quality of life outcomes following esophagectomy: A comparison between thorascopically assisted and open esophagectomy. Dis Esophagus. 2014;27:75A.

24. Lundell L. Quality of Life after Minimally Invasive Versus Open Esophagectomy. World J Surg. 2015;39:2109-10.

25. Zeng J, Liu JS. Quality of life after three kinds of esophagectomy for cancer. World J Gastroenterol. 2012;18:5106-13.

26. Shen H, Wang J, Li W, Yi W, Wang W. Assessment of health-related quality of life of patients with esophageal squamous cell carcinoma following esophagectomy using EORTC quality of life questionnaires. Mol Clin Oncol. 2015;3:133-8.

27. Sundaram A, Geronimo JC, Willer BL, Hoshino M, Torgersen Z, Juhasz A, Lee TH, Mittal SK. Survival and quality of life after minimally invasive esophagectomy: a single-surgeon experience. Surg Endosc. 2012;26:168-76.

28. Fujita T, Okada N, Sato T, Mayanagi S, Kanamori J, Daiko H. Translation, validation of the EORTC esophageal cancer quality-of-life questionnaire for Japanese with esophageal squamous cell carcinoma: analysis in thoracolaparoscopic esophagectomy versus open esophagectomy. Jpn J Clin Oncol. 2016:46:615-21.

29. Reynolds JV, McLaughlin R, Moore J, Rowley S, Ravi N, Byrne PJ. Prospective evaluation of quality of life in patients with localized oesophageal cancer treated by multimodality therapy or surgery alone. $\mathrm{Br}$ J Surg. 2006:93:1084-90.

30. Blazeby JM, Farndon JR, Donovan J, Alderson D. A prospective longitudinal study examining the quality of life of patients with esophageal carcinoma. Cancer. 2000;88:1781-7.

31. de Boer AG, van Lanschot JJ, van Sandick JW, Hulscher JB, Stalmeier PF, de Haes JC, Tilanus HW, Obertop H, Sprangers MA. Quality of life after transhiatal compared with extended transthoracic resection for adenocarcinoma of the esophagus. J Clin Oncol. 2004:22:4202-8.

32. Levenstein S, Li Z, Almer S, Barbosa A, Marquis P, Moser G, Sperber A, Toner B, Drossman DA. Cross-cultural variation in disease-related concerns among patients with inflammatory bowel disease. Am J Gastroenterol. 2001;96:1822-30.

33. Viklund $P$, Lindblad M, Lagergren J. Influence of surgery-related factors on quality of life after esophageal or cardia cancer resection. World J Surg. 2005;29:841-8.

34. Djarv T, Lagergren J, Blazeby JM, Lagergren P. Long-term health-related quality of life following surgery for oesophageal cancer. Br J Surg. 2008;95:1121-6.

35. Blazeby JM, Williams MH, Brookes ST, Alderson D, Farndon JR. Quality of life measurement in patients with oesophageal cancer. Gut. 1995:37:505-8.

36. Blazeby JM, Sanford E, Falk SJ, Alderson D, Donovan JL. Health-related quality of life during neoadjuvant treatment and surgery for localized esophageal carcinoma. Cancer. 2005;103:1791-9. 
37. Ariga H, Nemoto K, Miyazaki S, Yoshioka T, Ogawa Y, Sakayauchi T, Jingu K, Miyata G, Onodera K, Ichikawa H, et al. Prospective comparison of surgery alone and chemoradiotherapy with selective surgery in resectable squamous cell carcinoma of the esophagus. Int J Radiat Oncol Biol Phys. 2009;75:348-56.

38. Rosmolen WD, Boer KR, de Leeuw RJ, Gamel CJ, van Berge Henegouwen MI, Bergman JJ, Sprangers MA. Quality of life and fear of cancer recurrence after endoscopic and surgical treatment for early neoplasia in Barrett's esophagus. Endoscopy. 2010;42:525-31.

39. Borenstein M, Hedges LV, Higgins JPT, Rothstein HR. Introduction to metaanalysis. Chichester: Wiley; 2009.

40. Moher D, Pham B, Lawson ML, Klassen TP. The inclusion of reports of randomised trials published in languages other than English in systematic reviews. Health Technol Assess. 2003;7:1-90.

Submit your next manuscript to BioMed Central and we will help you at every step:

- We accept pre-submission inquiries

- Our selector tool helps you to find the most relevant journal

- We provide round the clock customer support

- Convenient online submission

- Thorough peer review

- Inclusion in PubMed and all major indexing services

- Maximum visibility for your research

Submit your manuscript at www.biomedcentral.com/submit
Biomed Central 